OPEN ACCESS

Edited by:

Toshihisa Murofushi,

Teikyo University Mizonokuchi

Hospital, Japan

Reviewed by:

Yasuyuki Nomura

Nihon University, Japan

Eliane Schochat,

University of São Paulo, Brazil

*Correspondence:

Qin Hong

rambler_hq@163.com

Xia Chi

chixia2001@njum.edu.cn

†These authors share first authorship

Specialty section: This article was submitted to Neuro-Otology,

a section of the journal

Frontiers in Neurology

Received: 09 April 2021

Accepted: 07 July 2021

Published: 23 August 2021

Citation:

Liu P, Zhu H, Chen M, Hong Q and Chi X (2021) Electrophysiological

Screening for Children With Suspected Auditory Processing Disorder: A Systematic Review.

Front. Neurol. 12:692840. doi: 10.3389/fneur.2021.692840

\section{Electrophysiological Screening for Children With Suspected Auditory Processing Disorder: A Systematic Review}

\author{
Panting Liu ${ }^{1 \dagger}$, Huiqin $\mathrm{Zhu}^{2 \dagger}$, Mingxia Chen ${ }^{3}$, Qin Hong ${ }^{2 *}$ and Xia Chi ${ }^{2 *}$ \\ ${ }^{1}$ School of Nursing, Nanjing Medical University, Nanjing, China, ${ }^{2}$ Department of Child Health Care, The Affiliated Obstetrics \\ and Gynecology Hospital of Nanjing Medical University, Nanjing Maternity and Child Health Care Hospital, Nanjing, China, \\ ${ }^{3}$ School of Nursing, Naniing Medical University, Nanjing, China
}

Objective: This research aimed to provide evidence for the early identification and intervention of children at risk for auditory processing disorder (APD). Electrophysiological studies on children with suspected APDs were systematically reviewed to understand the different electrophysiological characteristics of children with suspected APDs.

Methods: Computerized databases such as PubMed, Cochrane, MEDLINE, Web of Science, and EMBASE were searched for retrieval of articles since the establishment of the database through May 18, 2020. Cohort, case-control, and cross-sectional studies that evaluated the literature for the electrophysiological assessment of children with suspected APD were independently reviewed by two researchers for literature screening, literature quality assessment, and data extraction. The Newcastle-Ottawa Scale and 11 entries recommended by the Agency for Healthcare Research and Quality were used to evaluate the quality of the literature.

Results: In accordance with the inclusion criteria, 14 articles were included. These articles involved 7 electrophysiological testing techniques: click-evoked auditory brainstem responses, frequency-following responses, the binaural interaction component of the auditory brainstem responses, the middle-latency response, cortical auditory evoked potential, mismatch negativity, and P300. The literature quality was considered moderate.

Conclusions: Auditory electrophysiological testing can be used for the characteristic identification of children with suspected APD; however, the value of various electrophysiological testing methods for screening children with suspected APD requires further study.

Keywords: auditory processing, auditory processing disorder, electrophysiological testing, children, systematic review, screening

\section{INTRODUCTION}

Central auditory processing is the perception of auditory information by the central auditory nervous system (CANS) and neurobiological activity in the processing of auditory information and its evoked auditory physiological potentials (1). The American Speech-Language-Hearing Association (ASHA), the American Academy of Audiology (AAA), and the British Society of 
Audiology (BSA) define perceptual processing deficits of auditory information by the CANS as a central auditory processing disorder (CAPD) (1-3). These children primarily exhibit difficulty with speech-in-noise comprehension, frequently demand repetition, and have associated auditory attention and auditory memory deficits (4). The proposal of an auditory processing deficit has resulted from complaints of hearing problems despite normal audiograms noted in the study by Bocca et al. (5). Auditory problems still occur at $0.5-1 \%$ in children with normal peripheral hearing (6). According to Chermak and Musiek, the prevalence of auditory processing deficits in children ranges from 2 to 3\% (7). Meanwhile, the presence of auditory processing abnormalities in children with learning difficulties reaches $30-50 \%$ (8). Auditory processing deficits are often comorbid with other mental developmental disorders (9-12). Children with speech delay, dyslexia, and ADHD are often accompanied by relatively poor auditory processing skills (13-15), and children with auditory processing deficits may face problems with language, learning, and social communication.

Auditory processing deficits stem from impaired neural function in the CANS $(1,2)$; meanwhile, the plasticity of the brain structure and function can activate neurons or form effective synaptic connections within the brain (16). Performing top-down auditory training can effectively improve auditory processing in children with auditory processing deficits $(17,18)$. Therefore, the early identification of children with abnormal auditory processing, followed by an auditory intervention, bears clinical significance.

Current assessment methods used to identify abnormalities in the auditory processing function in children include subjective behavioral tests and objective electrophysiological tests (19). Subjective behavioral tests are divided into verbal and nonverbal tests, such as auditory discrimination tests, temporal processing tests, binaural interaction tests, dichotic speech tests, and monaural low-redundancy speech tests, among others (1). The diagnostic criteria for APD recommended by ASHA are as follows: in the behavioral testing battery, at least two or more behavioral test results, two standard deviations below the mean on either one or both ears $(1,7)$ or in one test, three standard deviations below the mean on both ears. In addition, several audiologists with extensive experience in the clinical evaluation of auditory processing also reached a consensus on this criterion $(8,20,21)$. This criterion assesses auditory processing skills in children by using at least two or more behavioral testing methods while supplying information beyond auditory processing deficits and provides a basis for individualized interventions (2). However, the use of behavioral tests as diagnostic criteria for APD yields inconclusive results $(22,23)$. Wilson assessed auditory processing in 150 children by using nine sets of diagnostic criteria for behavioral tests; the prevalence of suspected auditory processing disorder (sAPD) ranged from 7.3 to $96.0 \%$ (22). No uniform standards have been established in the current screening for auditory processing $(1,2,24)$; meanwhile, the sensitivity and specificity of various subjective behavioral tests have not been clarified because of the heterogeneity of auditory processing deficits (7). However, the current gold standard for the diagnosis of CAPD has not been established, leading to controversy over the definition and use of $\operatorname{APD}(25,26)$. The abnormal performance of children with auditory processing deficits in life and the challenges presented are undeniable; thus, effective screening tools for auditory processing have to be further explored.

The AAA practice guidelines indicate the clinical value of auditory electrophysiological testing in screening children for APD (2). Objective electrophysiological testing partly compensates for the inadequacy of behavioral testing, which (i) provides more objective results regardless of the level of language, attention, and cognition of the child and (ii) and owing to the faster development of the CANS (27), electrophysiological testing can be used when unable to cooperate with the completion of behavioral testing and the evaluation of auditory processing in younger children while enabling the early screening of children with sAPD. Owing to its advantages, auditory electrophysiological testing has gained increasing attention from audiologists and clinicians in hearing processing assessment but the clinical application of electrophysiological testing remains more limited because of the lack of supporting evidence. Currently, systematic reviews of behavioral tests for auditory processing screening have been conducted $(28,29)$; by contrast, no systematic review has been performed on the results of different electrophysiological tests in children with abnormal auditory processing. Thus, the current study provides a supportive basis for selecting screening tools for electrophysiological tests in children with sAPD through a systematic review of the clinical use of different electrophysiological tests in children with abnormal auditory processing.

\section{METHODS}

\section{Search Strategy}

Computer searches of the databases PubMed, Cochrane, Medline, Web of Science, and EMBASE were performed from their inception to May 18, 2020 by using the search terms "auditory processing, "auditory processing disorder," "electrophysiology," "event-related potential," "evoked potential," "auditory evoked response," "AER," "auditory brainstem response," “ABR," “cortical response" "P300," "Biomark," "mismatch negativity response," "MMN," "auditory middle latency response," "AMLR," “auditory late response," and "ALR.”

\section{Inclusion and Exclusion Criteria}

The inclusion criteria were as follows: (1) Study subjects included children with APD or children with sAPD who had normal peripheral hearing; (2) The testing method conducted was electrophysiological testing; (3) Study types included cohort, case-control, and cross-sectional studies; and (4) The articles were published in English.

Exclusion criteria: (1) Study subjects included neonates or adults and those diagnosed with the disease or in combination with other mental developmental disorders, such as ADHD, ASD, dyslexia, language impairment; (2) Reviews and republications; and (3) Animal experimental studies. 


\section{Literature Screening, Extraction and Evaluation}

In accordance with the inclusion and exclusion criteria, two authors independently screened the literatures. After the duplicate articles were deleted, the literatures were screened by reading the title and abstract of the literatures. For inconclusive literatures, the third author mediated and jointly decided. Finally, the literatures that met the inclusion criteria were retained based on the full reading of the text. Data were extracted independently by two authors and included the following: author, research object, sample size, electrophysiological testing method, results, and conclusion. Two authors used 11 items recommended by the Agency for Healthcare Research and Quality (30) to evaluate the literature quality of the cross-sectional study; a "no" or "unclear" response was assigned a score of "0," whereas a "yes" response was assigned a score of " 1 ." The Newcastle-Ottawa Scale (31) was used to evaluate the quality of cohort studies and case-control studies, and $a \star$ was assigned a score of “1” (Table $\mathbf{1}$ ).

\section{RESULT}

A total of 1,202 articles were retrieved from five databases, as follows: PubMed (22), Cochrane (328), MEDLINE (41), Web of Science (251), and EMBASE (560). In accordance with the inclusion and exclusion criteria, 14 articles were selected using the screening process shown in Figure 1. The 14 articles included 7 electrophysiological tests: click-evoked auditory brainstem responses (click ABR), frequency-following responses (FFR), binaural interaction component of the auditory brainstem responses (BIC of $A B R$ ), the middle-latency response (MLR), the cortical auditory evoked potential (CAEP), mismatch negativity $(\mathrm{MMN})$, and P300. All aforementioned electrophysiological tests were conducted on participants aged 5-18 years. The literature quality was moderate.

\section{Click-Evoked Auditory Brainstem Responses}

The click ABR is an objective electrophysiological test widely used to assess hearing threshold and brainstem neural integrity $(46,47)$. Ankmnal-Veeranna et al. retrospectively compared 108 children with sAPD and 22 normal children for auditory brainstem response recording (32). Recording of click ABR in this study consisted of a slow stimulus (13.3 beats/s) and a fast stimulus (57.7 beats/s) presented to the left and right ears via headphones at an acoustic stimulus of $80 \mathrm{dBnHL}$, and the typical clinical indexes (latency and interpeak interval of waves I, III, and $\mathrm{V}$ ) were analyzed. Wave I latencies were significantly longer in children with sAPD than those in normal children $(P=$ 0.027 ), whereas wave III and V latencies were not statistically different between the two groups. No significant difference in the interwave interval was observed between children with sAPD and normal children, except for a prolonged mean interval ( $>2$ standard deviations above normal) in individual children with sAPD. The children with sAPD were less stable than the normal children $(P=0.039)$. The $\mathrm{ABR}$ is a useful tool for exploring the integrity of auditory brainstem pathways but has not been widely used for auditory processing assessment because of the lack of supporting evidence (23). In addition, the sAPD children included in the Ankmnal-Veeranna et al. study were not identified by an evaluation with the recommended behavioral testing battery; instead, they were referred solely by physicians, community audiologists, parents, and family friends. They were assessed using the children auditory performance scale (48) and screening identification for targeting educational risk (49). These two subjective scales screen for children with pre-existing auditory problems. Thus, the value of click ABR for auditory processing assessment needs further validation.

\section{Frequency-Following Response}

Frequency-following Response (FFR) is an electrophysiological method that reflects the fidelity and precision of brain encoded sound (50). For many years, FFR has been confused with some terms, such as speech evoked ABR (sABR) and complex sounds evoked ABR (CABR). In order to unify the terms and avoid unnecessary differences among researchers, scholars suggest using a more accurate and appropriate term FFR (50). Therefore, we will use FFR as a substitute for speech evoked ABR (sABR) used by other authors.

FFR has increasingly gained research interest in recent years. Contrary to the traditional click and tone burst, FFR uses the complex syllable /da/ to evoke auditory brainstem response, which is mainly used to analyze the neural activity of the brainstem to speech stimulus (51). The FFR is highly reproducible in young adults (52) and tends to mature in children by age 5 (53). In 2017, Zakaria and Jalaei studied the testretest reliability of the FFR in normal schoolchildren (35). The test was conducted on 17 healthy children (6 males and 11 females) aged 5-9 years, using $30 \mathrm{~dB}$ SL, $40 \mathrm{~ms}$ speech sounds /da/ for low-level stimulation. After 3 months, the FFR test was repeated. No significant difference between the first and second FFR test was found $(P>0.05)$. Correlation analysis of the two recordings was performed; the peak latencies, peak amplitudes (V, A, C, D, E, F, O), and composite initiation indexes (V/A duration, V/A amplitude, and V/A slope) of the FFR were highly correlated, particularly the peak latencies of the FFR. In 2012, Hornickel et al. analyzed the speech /da/ evoked FFR in 26 normal children (aged 8-13 years) with an interval of 1 year, collected in a quiet environment and with background noise (sounds spoken by six individuals). Reaction times and spectral coding were found to be highly reproducible over a period of 1 year (40).

The FFR was first used in studies of children with learning disabilities and speech perception deficits (54). In 2014, RochaMuniz et al. analyzed the sensitivity, specificity, and efficiency of the FFR for the diagnosis of sAPD (39). The study included 25 children with sAPD and 25 normal children. Children with sAPD had subnormal results on two or more of the four behavioral test battery (the dichotic digits test, staggered spondaic words, speech-in-noise testing and frequency pattern testing) (1). FFR was induced by the syllable /da/, and the waveforms $\mathrm{V}, \mathrm{A}, \mathrm{C}, \mathrm{D}$, E, F, and $\mathrm{O}$ were analyzed. The latencies of waves V, A, C, and $\mathrm{O}$ were significantly prolonged in children with SAPD, relative to those in normal children. Wave cutoffs were determined by 
TABLE 1 | Data of selected articles, including study, sample, electrophysiological, results, conclusion and quality score.

\begin{tabular}{|c|c|c|c|c|c|}
\hline Study & Sample & Electrophysiological & Results & Conclusion & Quality score \\
\hline 1. Ankmnal-Veeranna et al. (32) & $\begin{array}{l}\text { G1: sAPD }(n=108,5.25-15.7 \\
\text { years, Mean age: } 9.63 \pm 2.70) \\
\text { G2: TD }(n=22,4.11-16.1 \\
\text { years, mean age: } 10.71 \pm 3.40)\end{array}$ & Click ABRs & $\begin{array}{l}\text { Children sAPD not } \\
\text { significant compared with } \\
\text { TD children. However, } \\
\text { individual children } \\
\text { SAPD showed clinically } \\
\text { significant delays }\end{array}$ & $\begin{array}{l}\text { This study provides } \\
\text { supportive evidence for } \\
\text { the value of click-evoked } \\
\text { ABRs in comprehensive } \\
\text { auditory processing } \\
\text { assessment batteries }\end{array}$ & AHRQ: 7 \\
\hline 4. Zakaria and Jalaei (35) & $\begin{array}{l}\text { Age: } 5-9 \text { years (mean }=6.8 \pm \\
3.3 \text { years) } \\
N=17 \text { ( } 6 \text { males, } 11 \text { females) } \\
\text { Healthy and no } \\
\text { hearing difficulties }\end{array}$ & FFR & $\begin{array}{l}\text { No significant differences } \\
\text { in all FFR results between } \\
\text { first and second sessions } \\
(p>0.05)\end{array}$ & $\begin{array}{l}\text { Highly stable FFR results } \\
\text { (peak latencies, peak } \\
\text { amplitudes, and } \\
\text { composite onset } \\
\text { measures) over the period } \\
\text { of } 3 \text { months }\end{array}$ & NOS: 7 \\
\hline 7. Kumar and Singh (38) & $\begin{array}{l}\text { Age: } 8-12 \text { years } \\
\text { G1: Abnormal AP ( } n=15,8 \\
\text { males; } 7 \text { females, mean age: } \\
9.87 \pm 1.35) \\
\text { G2: age-matched typically } \\
\text { developing children }(n=15,8 \\
\text { males; } 7 \text { females, mean } \\
\text { age:9.33 } \pm 1.45) \\
\text { Had normal hearing sensitivity }\end{array}$ & FFR (Biomark) & $\begin{array}{l}\text { Significant prolongations } \\
\text { of wave } V \text { and } A \text { latencies } \\
(p=0.001) \text { and marginal } \\
\text { reductions in } V / A \text { slope }(p \\
=0.052) \text { and amplitude of } \\
\text { responses to first formant } \\
(p=0.065)\end{array}$ & $\begin{array}{l}\text { FFR, through the use of } \\
\text { BioMARK protocol, could } \\
\text { clearly demarcate } \\
\text { between children at risk } \\
\text { for CAPD and typically } \\
\text { developing } \\
\text { Children, exhibiting great } \\
\text { potential as an } \\
\text { electrophysiological tool } \\
\text { for the assessment of } \\
\text { such individuals }\end{array}$ & AHRQ: 7 \\
\hline
\end{tabular}


TABLE 1 | Continued

\begin{tabular}{|c|c|c|c|c|c|}
\hline Study & Sample & Electrophysiological & Results & Conclusion & Quality score \\
\hline 8. Rocha-Muniz et al. (39) & $\begin{array}{l}\text { Age: } 6-12 \text { years } \\
N=75 \text { (had normal hearing) } \\
\text { G1: TD ( } n=25 ; 8.80 \pm 2.08 \\
\text { years; } 12 \text { males and } 13 \\
\text { females) } \\
\text { G2: APD ( } n=25 ; 8.72 \pm 1.67 \\
\text { years; } 18 \text { males and } 7 \text { females) } \\
\text { G3: SLI ( } n=25 ; 7.84 \pm 1.77 \\
\text { years; } 18 \text { males and } 7 \text { females) }\end{array}$ & FFR & $\begin{array}{l}\text { The A wave exhibited } \\
\text { superior balance for the } \\
\text { APD group ( } 68 \% \\
\text { specificity, } 80 \% \text { sensitivity, } \\
\text { and } 74 \% \text { accuracy) }\end{array}$ & $\begin{array}{l}\text { FFR is a useful test to } \\
\text { identify auditory } \\
\text { processing disorders }\end{array}$ & AHRQ: 6 \\
\hline 9. Hornickel et al. (40) & $\begin{array}{l}\text { Age: } 3-18 \text { years (mean age: } \\
10.5 \text { years, } 14 \text { males } 12 \\
\text { females) } \\
N=26 \text { (typically-developing } \\
\text { children, had normal hearing }\end{array}$ & FFR & $\begin{array}{l}\text { Highly replicable response } \\
\text { timing and spectral } \\
\text { encoding over the course } \\
\text { of } 1 \text { year }\end{array}$ & $\begin{array}{l}\text { The FFR may be a unique } \\
\text { tool for research and } \\
\text { clinical assessment of } \\
\text { auditory function, } \\
\text { particularly in auditory } \\
\text { communication skills }\end{array}$ & NOS: 6 \\
\hline 11. Roggia and Colares (42) & $\begin{array}{l}\text { Age: } 9-14 \text { years } \\
N=16 \\
\text { G1: APD children }(n=8) \\
\text { G2: normal children }(n=8) \\
\text { Had normal hearing }\end{array}$ & MMN & $\begin{array}{l}\text { No significant differences } \\
\text { in latency and amplitude } \\
\text { values among children } \\
\text { with APD }\end{array}$ & $\begin{array}{l}\text { The CAPD individuals } \\
\text { evaluated showed no } \\
\text { changes in MMNf or } \\
\text { MMNd } \\
\text { MMN could not be } \\
\text { considered as a measure } \\
\text { of the presence or } \\
\text { absence of hearing } \\
\text { disorders in CAPD } \\
\text { subjects }\end{array}$ & AHRQ: 6 \\
\hline 13. Delb et al. (44) & $\begin{array}{l}\text { Age: } 6-12 \text { years } \\
N=60 \\
\text { G1: sAPD children }(n=17 \\
\text { mean: } 8.8 \pm 1.6) \\
\text { G2: normal children }(n=25 \\
\text { mean: } 8.8 \pm 1.4) \\
\text { Had normal hearing }\end{array}$ & $\mathrm{BIC}$ of $\mathrm{ABR}$ & $\begin{array}{l}76 \% \text { sensitivity and } \\
\text { specificity could be } \\
\text { achieved }\end{array}$ & $\begin{array}{l}\text { BIC measurements might } \\
\text { be of some diagnostic } \\
\text { value in CAPD patients }\end{array}$ & AHRQ: 5 \\
\hline
\end{tabular}


TABLE 1 | Continued

\begin{tabular}{|c|c|c|c|c|c|}
\hline Study & Sample & Electrophysiological & Results & Conclusion & Quality score \\
\hline 14. Jirsa and Clontz (45) & $\begin{array}{l}\text { Age: } 9.2-11.6 \text { years } \\
N=36 \\
\text { G1: CAPD children }(n=18) \\
\text { G2: normal children }(n=18)\end{array}$ & CAEP and P 300 & $\begin{array}{l}\text { Significant increases in } \\
\text { latency for the N1, P2, } \\
\text { and P3 components in the } \\
\text { processing disordered } \\
\text { group } \\
\text { The interpeak latency } \\
\text { interval P2-P3 was } \\
\text { significantly longer in the } \\
\text { clinical group }\end{array}$ & $\begin{array}{l}\text { The long-latency } \\
\text { potentials may be useful in } \\
\text { the assessment of } \\
\text { children with processing } \\
\text { disorders }\end{array}$ & AHRQ: 7 \\
\hline
\end{tabular}

G, group; TD, typically developing; AP, auditory processing; $A P D$, auditory processing disorder; sAPD, suspected auditory processing disorder; ABR, auditory brainstem responses; $B I C$, binaural interaction component; $M L R$, middle-latency response; CAEP, cortical auditory evoked potential; MMN, mismatch negativity; FFR, frequency-following response; AHRQ, Agency for Healthcare Research and Quality; NOS, Newcastle-Ottawa Scale.

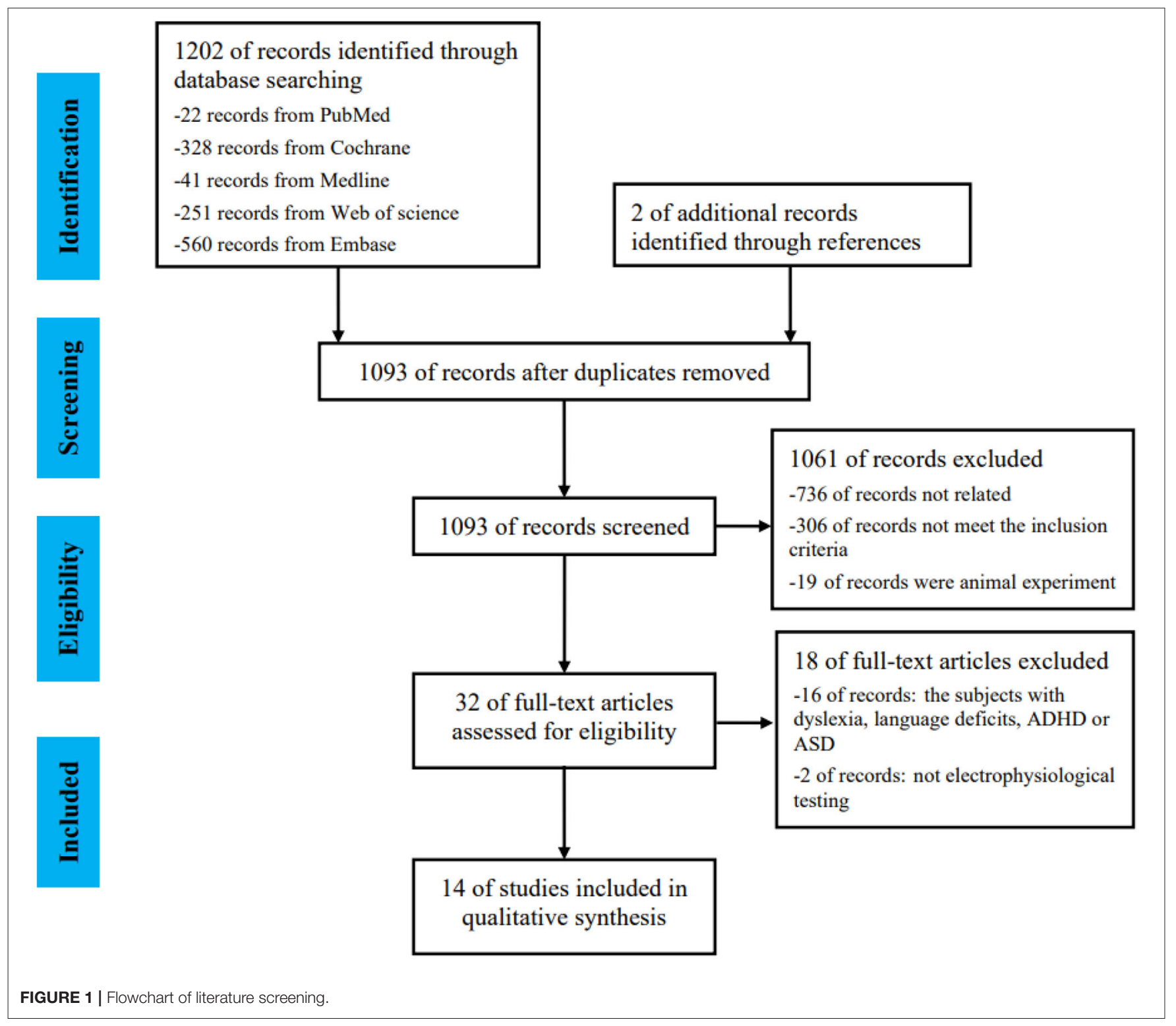


analyzing receiver operating characteristic (ROC) curves. The Awave sensitivity was $80 \%$, and specificity was $68 \%$. The accuracy of the identification of sAPD was $74 \%$.

In 2016, Rocha-Muniz et al. once again explored the clinical utility of FFR (36), A total of 27 children (aged 7-15 years) with an abnormal FFR were evaluated based on 5 tests of the auditory processing behavior, including sound localization, sequential memory for non-verbal sounds, sequential memory for verbal sounds, speech perception in noise or identification of figures with noise, staggered spondaic word test, frequency and duration pattern tests, and gaps in noise. The results showed that at least one behavioral test abnormality was present in 23 of 27 children with abnormal FFR. This study determined an $85.15 \%$ probability of auditory processing deficits in children with abnormal FFR. This calculation is similar to previous findings (39). However, one limitation of this study is the small sample size.

The FFR has been used to explore brainstem encoding of speech signals in children with dyslexia $(38,55)$, language impairment (56, 57), and learning problems (58-60). However, studies on children with isolated auditory processing abnormalities have rarely been reported. The study of FFR in children with auditory processing abnormalities requires the exclusion of children with higher-order functional deficits, considering that auditory processing abnormalities often coexist with neurodevelopmental disorders, such as language impairment, ADHD, and learning disabilities. In 2015, Kumar et al. first explored BioMark (commercialized FFR) in children with sAPD in whom dyslexia had been excluded (38). The results showed that BioMark waveform morphology was poorer in the presence of children at risk for APD, compared with normal children. Moreover, intergroup comparison indicated that $\mathrm{V}$ and $\mathrm{A}$ wave latencies were significantly longer in the presence of children at risk for APD $(P=0.001)$. These results suggest the validity of the FFR as an electrophysiological tool for the evaluation of auditory processing. However, Kumar used only the auditory processing screening scale as a tool to identify children with SAPD. Although the scale exhibited high sensitivity and specificity, it also merely stated that these children might be at risk for APD.

\section{BIC of Auditory Brainstem Responses}

The binaural interaction component (BIC) represents the difference between the sum of the monaural evoked potentials and the binaural evoked potentials. Binaural interaction (BI) supports sound localization and auditory behavior under noise and competing acoustic signals at the brainstem level. Electrophysiological testing with BIC is used to evaluate central auditory system abnormalities (61). Gopal and Pierel showed a significant reduction in the BIC amplitude of auditory brainstem responses in children with language disorder and at risk for APD (62). Delb et al. reported on the sensitivity and specificity of the BIC of the auditory brainstem response as a discriminator between children with sAPD and normal children (44). The BIC test was performed on 60 children, divided into the sAPD group $(n=17,8.8 \pm 1.6$ years $)$ and the normal group $(n=25,8.8 \pm 1.4$ years $)$ by three behavioral tests: dichotic testing, speech discrimination in noise, and binaural fusion testing. The sensitivity and specificity of the $B$ component of the BIC as an index for discriminating between children with sAPD and normal children were $76 \%$ when subjects underwent 4,000 alternating stimulations of both ears or one ear at $65 \mathrm{~dB} \mathrm{HL}$ and $60 \mathrm{~ms}$ interstimulus intervals.

\section{Middle-Latency Response}

The middle-latency component mainly represents potentials from the thalamus and the primary auditory cortex (63). In 2010, Schochat et al. examined the characteristics of MLRs in 30 children with sAPD, aged 8-14 years (41). At least one ear of the 30 sAPD children's pediatric speech intelligibility test (64), speech-in-noise test (65), staggered spondaic word test (66), the dichotic digit test (67), and the dichotic non-verbal test (65) was lower than the average in two tests. Compared with 22 normal children aged 8-14 years, those with sAPD showed significantly lower $\mathrm{Na}, \mathrm{PA}$, and $\mathrm{Pb}$ amplitudes at $\mathrm{C} 3$ A1 and C3-A2. In the children with sAPD subjected to auditory training for 8 weeks, the amplitudes increased to values similar to those in normal children. Therefore, the MLR is important in identifying children with sAPD and evaluating the efficacy of interventions.

In 2019, Abdollahi et al. identified 60 children with sAPD, aged 8-12 years, in accordance with multiple auditory processing assessment test batteries. These 60 children with sAPD were compared with 60 normal children with respect to the middlelatency response (MLR) and its BIC (33). Significant differences in PA and $\mathrm{Na}$ latency (ms), PA and $\mathrm{Na}$ amplitude (lv), BIC latency (ms), and BIC amplitude (lv) were determined between children with sAPD and normal children $(P \leq 0.001)$. All waveform latencies were greater and all amplitudes were lower in children with sAPD than in normal children $(P \leq 0.001)$. Therefore, the BIC of MLR and MLR are valuable for identifying potential children with sAPD.

\section{Cortical Auditory Evoked Potential}

As an auditory long-latency response, cortical auditory evoked potential (CAEP) has been used to examine the function of the central auditory system in children with language disorder (68), learning disability (55), and hearing loss (69). The P1-N1 complex components of the CAEP are often used to track the maturation of the central auditory system in hearing-impaired children $(70,71)$, Tomlin contrasted the CAEP between 27 children with SAPD, aged 7-12 years as determined using AAArecommended behavioral test battery and 22 matched normal children (37). Presented to the left and right ears as tone burst stimuli at $80 \mathrm{~dB} \mathrm{HL}, 500 \mathrm{~Hz}$, waves P1 and N1 were detected in all children. Compared with normal children, children with sAPD showed increases in P1 and N1 latencies by about $10 \mathrm{~ms}$ $(P<0.05)$ and a decrease in $\mathrm{P} 1-\mathrm{N} 1$ amplitude by about $10 \mu \mathrm{V}$ $(P=0.03)$, whereas no significant difference in the subsequent $\mathrm{P} 2$ waves was found between the two groups. P1-N1 complex components may be valid markers of auditory cortex maturity in children with sAPD. In 2003, Liasis et al. compared the ERPs in 9 children with sAPD and 9 normal children in the SCAN/SCAN-A test (43). N1 latency was significantly longer in 
sAPD children than in normal children, as determined using speech $/ \mathrm{ba} /$ as the standard stimulus $(P=0.04)$. On the basis of the wave morphology, the peak-to-peak amplitudes of P85$120-\mathrm{N} 1$ and $\mathrm{P} 2-\mathrm{N} 2$ were larger $(P=0.007)$, whereas the peakto-peak amplitudes of N1-P2 were smaller in the SAPD children $(P=0.004)$.

The central auditory system processes verbal and non-verbal stimuli differently (72). Consequently, different response patterns can be generated using different types of stimuli. In 2017, Koravand et al. used the "oddball" paradigm for verbal and non-verbal stimuli to record CAEPs (34). The study population included 13 children with sAPD and 10 normal children. The results showed that $\mathrm{P} 1$ and $\mathrm{N} 2$ waves were observable in all children, and the N2 latency of speech / da/ evoked was longer than that of non-verbal $/ \mathrm{da} /$ evoked $(P<0.016)$, and was significantly longer in children with sAPD compared with normal children $(P<0.001)$. During $2 \mathrm{kHz}$ pure tone stimulation, the N2 amplitude was significantly reduced in children with sAPD $(P<0.01)$. However, P1 latency and amplitude were not statistically different between the two groups. The abnormal N2 latency and amplitude may reflect the immaturity of the cerebral cortex in the sAPD children. In addition, the N2 latency evoked by simple stimuli varies from that evoked by complex stimuli. This difference indicates that the central auditory system needs additional time and effort to deal with complex stimuli. A small number of children with hearing processing disorders were included in the study, considering that those with comorbidities, such as children with language and reading difficulties, were excluded.

\section{Mismatch Negativity}

Mismatch negativity (MMN) is an auditory evoked potential with the long-latency response that reflects the early sensory stage of sound processing, the underlying auditory perceptual mechanism (73). It is the difference obtained when auditory event-related potentials obtained with a standard stimulus are subtracted from those obtained with a target stimulus (74). In 2003, Liasis et al. investigated cortical auditory responses in 9 schoolchildren with sAPD (children suspected with APD, based on the clinical presentation and SCAN/SCAN A test) and 9 normal children (43). Speech stimuli consisted of $76 \%$ standard stimuli $(/ \mathrm{ba} /)$ and $24 \%$ target stimuli (/da/). No significant differences in MMN latency and peak amplitude were found between children with sAPD and normal children, which was similar to that reported by Roggia and Colares (42). Moreover, no significant differences in the latency or amplitude of MMN were determined between the 8 children with sAPD (as determined by an audiological behavioral assessment in an audiology clinic) and the 8 normal children in whom MMN was evoked with stimuli of different frequencies and durations (standard stimulus, $750 \mathrm{~Hz}, 100 \mathrm{~ms}$; target stimulus, $1,000 \mathrm{~Hz}, 50 \mathrm{~ms}$ ). These results were consistent with the study by Koravand et al. (34), which used non-verbal and verbal stimuli to record CAEPs and involved 23 children, aged 9-12 years. The participants consisted of 10 children with sAPD and 13 normal children. Ten children with SAPD scored below the mean in at least one ear in one test in the behavioral testing battery that included the French adaptation of the Staggered Spondaic Word Test (75), the French adaptation of the Synthetic Sentence Identification-Ipsilateral Competing Message Test (76), the Pitch Pattern Test (77), the Duration Pattern Test (77), and the Random Gap Detection Test (78), with $85 \%$ probability for standard stimuli (speech $/ \mathrm{ba} /$, nonverbal $/ \mathrm{ba} /$, and $1 \mathrm{kHz}$ pure tones) and $15 \%$ for target stimuli (speech/da/, non-verbal/da/, and $2 \mathrm{kHz}$ pure tones). The results showed no significant difference in MMN between the two groups. Therefore, the current study cannot yet demonstrate that MMN is a reliable electrophysiological tool for screening children with auditory processing defects.

\section{P300}

P300 is an important endogenous component in the eventrelated potential (ERP) that responds to high-level cognitive functions in the brain. It is widely studied and has broad clinical applications. Abnormalities in P300 were found in children with cognitive impairment and language disorder, in contrast to normal children $(79,80)$. In 1990 , Jirsa and Clontz applied ERP in the evaluation of children with abnormalities in central auditory processing (45). The study included 8 normal children and 8 sAPD children who scored below the normal response range in at least one ear during behavioral testing (the selective auditory attention competing subtest, pitch pattern sequence test for children-verbal response, pitch pattern sequence test for children-hummed response, and competing sentence test). The 16 aforementioned children showed normal peripheral hearing and normal ABR trajectories. The test stimulus sound at 65 $\mathrm{dB}$ HL was presented to both ears in a random sequence, including $20 \%$ of the $2 \mathrm{kHz}$ target stimulus and $80 \%$ of the $1 \mathrm{kHz}$ standard stimulus. In the test, all children performed the task of distinguishing and counting sounds and were able to produce the P300 waveform. The results indicated that the latencies of N1, P2, and P3 components were significantly increased in the sAPD group. In addition, the peak-to-peak latency P2-P3 in the SAPD children was significantly prolonged, whereas the amplitude of $\mathrm{P} 3$ was significantly decreased. These results suggest that ERP, particularly P3, can be used to evaluate children with auditory processing impairment; however, $\mathrm{P} 300$ is affected by the attention and cognitive level of children and cannot be elicited in young children.

\section{DISCUSSION}

Auditory processing deficits originate from abnormalities in the development of the central auditory system, with increased emphasis on auditory deficits that are not the result of higherlevel cognitive, language, or other related disorders. Auditory processing deficits also fail to cause all learning, language, and social problems (81). The central auditory nervous system is a complex structure with a parallel afferent and a hierarchical afferent (82). The central nervous system has a major function and is responsible for memory, attention, language, and other functions. The auditory system shares neuroanatomical bases and processing with other systems; thus, children with auditory processing deficits often have language $(10,83,84)$, attention (85-87), and memory problems $(14,85,88,89)$. The plasticity 
of the central auditory nervous system renders the auditory training effective in improving auditory processing skills in children with APD $(17,90)$. Therefore, the early identification and intervention of children with auditory processing defects are important. Auditory processing assessment plays an important role in determining the severity of impaired auditory processing function in children with APD and guiding the construction of individualized intervention protocols (2). Studies have shown that the correlation between the results of the auditory processing behavior test and the electrophysiological test is not considerably high (91). Moreover, the behavioral tests present larger individual differences because auditory behavioral tests require the participation of subjective factors, such as children's language, attention, cognition, and so on. Thus, when children have auditory processing deficits that coexist with other deficits, subjective behavioral tests may be affected by nonauditory factors, influencing the accuracy of the test results. Meanwhile, screening for auditory processing with more than one behavioral test has been associated with enhanced sensitivity but reduced specificity because of the heterogeneity of auditory processing (2). Behavioral tests are more demanding for children, and their test results are more stable only for those aged 7 years and older (2). For younger children, potential auditory processing problems are solved by electrophysiological testing as an objective and reliable means of auditory processing assessment (2), rather than waiting until they reach a testable age. Simultaneously, objective electrophysiological tests are gaining popularity among investigators and clinicians, and ASHA recommends the addition of electrophysiological tests to the evaluation of auditory processing (1). Parthasarathy clarified that auditory electrophysiological measures be included in each central auditory testing battery because they provide objective evidence of central auditory system dysfunction (92). However, the current clinical use of electrophysiological testing remains relatively limited. In the current study, the electrophysiological characteristics of children with sAPD were analyzed using a systematic review of the relevant literature to provide supportive evidence for the selection of electrophysiological assessment tools and evaluation of the efficacy of interventions in children with auditory processing deficits.

The 14 studies that were ultimately considered in this review included 7 electrophysiological tools for auditory processing assessment, which involved the short-latency response, MLR, and the long-latency response of auditory evoked potentials. These responses reflect the auditory functions of the brainstem, thalamus, and auditory cortex of the central auditory system, respectively.

\section{Short-Latency Response}

Auditory brainstem response (ABR) is the most commonly used testing method in short-latency auditory evoked potentials. This systematic review includes seven studies on short-latency auditory evoked potentials, including one study on $A B R$ evoked by simple stimuli, one study on Binaural Interaction Component of ABR, and five studies on FFR evoked by complex speech sounds.
Click ABR is an important index clinically used to detect auditory function and provides information about the functional integrity of brainstem auditory pathways $(93,94)$. Abnormalities in the latencies and amplitudes of the ABR imply the impaired integrity of the auditory pathways $(95,96)$. ABR matures earlier (32) and is not affected by the state of consciousness of the child; as such, ABR is clinically more useful for monitoring the integrity of the auditory nerve in infants and young children. Although click ABR may be a useful electrophysiological tool in detecting auditory nerve integrity, its use for the identification of children with APD has not been clearly demonstrated. In the study by Ankmnal-Veeranna et al., click ABR latencies were not significantly prolonged in children with SAPD relative to those in normal children (32). The limitation of this study is that these children with sAPD had no standardized assessment of auditory processing only because of auditory problem referral and through the auditory processing questionnaire evaluation of children with SAPD. The more prominent performance characteristics of these sAPD children are probably not caused by the central auditory nervous system injury but overlap other defects. Therefore, more studies are needed to prove whether click ABR can be used to identify auditory processing defects.

FFR has drawn increasing interest among researchers (97, 98). The advantage of FFR is that compared with ABR evoked by simple stimuli, the syllable /da/ is more compliant with the acoustic characteristics of speech sounds and contains more verbal information (99). The FFR includes the transient components ( $\mathrm{V}, \mathrm{A}, \mathrm{C}$, and $\mathrm{O}$ ) and periodic components $(\mathrm{D}, \mathrm{E}$, and F) $(97,100,101)$ and primarily originates from neurons in brainstem nuclei (101). FFR exhibits good test-retest reliability and stability. Zakaria and Hornickel explored the testretest reliability of the FFR at intervals of 3 months and 1 year, respectively. All showed that the FFR improved stability and can provide distinct information for auditory processing studies and clinical assessment in children $(35,40)$. RochaMuniz conducted studies on the clinical use of the FFR in 2014 and 2016 and confirmed the validity of the FFR as an assessment tool for children with auditory processing deficits $(36,39)$. Future studies with larger samples are justified to verify the reliability of the results. FFR is widely used in dyslexic children $(57,102,103)$. Kumar first explored the value of the FFR as a screening tool for auditory processing when comorbidities were excluded (38). In addition, FFR can be used as a good index to evaluate the effectiveness of auditory training (104).

BICs, which reflect binaural interactions (105-107), have effectively responded to binaural processing functions $(108,109)$. Binaural processing is one of the important auditory processing behaviors and is associated with sound localization and lateralization and speech recognition in noise. Binaural processing impairment is one of the main manifestations of auditory processing defects. Therefore, the evaluation of binaural interaction is important for screening children at high risk for APD $(110,111)$, particularly when difficulty in sound localization is observed or when hearing in the presence of noise presents a challenge. 
The current study of BIC for ABR is extensive and confirms its reliability for assessing binaural processing $(112,113)$.

\section{Middle-Latency Response}

Only 2 studies on middle-latency auditory evoked potentials in children with SAPD were included in this systematic review, indicating that tests of middle-latency auditory evoked potentials are less frequently used in children with APD.

In the consensus meeting on the diagnosis of APDs in schoolage children, the inclusion of ABR and MLR in a minimal APD test battery was proposed (12). MLR is a sensitive indicator of CANS diseases and an important auditory evoked response for identifying auditory processing defects $(12,41,114)$. MLR provides information about the integrity of the central auditory system via the primary cortex. MLR is abnormal in children with learning disabilities and language impairment $(114,115)$. Schochat found that MLR amplitudes were smaller in children with SAPD than in normal children, whereas MLR amplitudes after the intervention increased to levels not significantly different from those of normal children (41). Abdollahi indicated that the BIC of MLR and MLR can be used to identify children with sAPD (33). Compared with that of ABR, the sensitive index for the MLR assessment of central auditory system development is amplitude rather than latency (116); meanwhile, the BIC of MLR is larger and easier to detect than the BIC of ABR. Similar to the ABR, the MLR is not affected by child attention (63). A middle-latency evoked potential has clinical application value in identifying children with SAPD and evaluating intervention effects. However, MLR and BIC of MLR in children with abnormal auditory processing are rarely reported. More studies on the application of middle-latency auditory evoked potentials in children with APD need to be conducted in the future.

\section{Late-Latency Responses}

ERP belongs to late-latency auditory evoked potential, including CAEP, MMN, and P300. ERP refers to the change in brain potential associated with a certain cognitive activity, which reflects the perception and processing ability of the CANS to auditory information (117). This systematic review includes 5 studies on the application of long-latency electrophysiological tests in children with SAPD, with each study potentially involving more than 1 electrophysiological test -4 studies on CAEP, 3 studies on MMN, and 1 study on P300.

The wave latency and amplitude of the CAEP represent the speed and amplitude of central auditory processing (118). Studies showing prolonged latencies and reduced amplitudes indicate a reduced number of contributing neurons, decreased synchronous responses, altered synaptic density, intracortical myelination, or altered structure/orientation of the auditory pathway (119). The CAEP early components P1 and N1 can be used as markers of auditory cortex maturity in children with auditory processing deficits (37). Unlike CAEP late components, $\mathrm{P} 1$ and N1 are passive and do not require the involvement of child attention (120). Liasis noted that the latency and morphology of the N1 wave differ in children with auditory processing deficits and normal children (43). The N1 wave is associated with the sudden appearance or occasional alteration in the frequency of stimulus sounds (121) and may reflect the variable sensitivity of the auditory cortex and cortical activity inside (122). The first component of the N1 wave is the onset of analysis of sensory information and may reflect the initiation of attention and memory formation (122). The P2 wave and the late component of the CAEP are not generated by the auditory cortex but by several sensory modalities (123). Other studies have shown that the source of the N2 wave may be related to the inhibitory response (124). Koravand et al. proposed that the N2 wave can be used as an effective discriminator of sAPD (34). Therefore, children with sAPD can potentially have an inhibitory processing defect.

Passively evoked MMN can provide objective measures for auditory discrimination and the automatic processing of perception (125). Contrary to $\mathrm{P} 300$, the MMN was not be affected by subject attention. MMN can be used to assess the central auditory system function in children with dyslexia and autism spectrum disorder $(126,127)$; however, the value of $\mathrm{MMN}$ as a screen in children with sAPD has not been demonstrated.

The endogenous component P300, which is produced in areas other than subcortical structures and temporal lobes, is involved in the attention to and recognition of stimulus sound differences. P300 may also be related to neural activities, such as the processing of sequence information, short-term memory, or decision-making (128). P300 can be used as a meaningful indicator to identify children at risk for APD. As reported by Jirsa and Clontz, children with SAPD showed significantly longer P300 latencies and significantly lower amplitudes compared with normal children (45). In addition, the P300 test can sensitively reflect changes in auditory processing ability (129), providing a reliable basis for the evaluation of auditory processing function and intervention efficacy. P300 maturation is influenced by the developmental level of the child, and its latency decreases with age; meanwhile, elicitation of the P300 wave requires active child participation, such as performing tasks to focus attention, and results are influenced by child attention, cognition, and psychological factors. Thus, abnormal P300 can occur in cases of SAPD but may also be observed in children with cognitive, attention, and other higherorder disorders. Therefore, the interpretation of P300 results in children with auditory processing deficits needs multidisciplinary collaboration to identify children with mental development disorders, such as language impairment, ADHD, and ASD. More electrophysiological studies of long-latency responses in children with auditory processing abnormalities are also needed.

A systematic review of the use of electrophysiological testing at different latencies in children with APD or SAPD showed that electrophysiological testing effectively identified children with auditory processing deficits, aiding the determination of the site and the origin of abnormalities of the central auditory nervous system. The short-latency auditory evoked potentials have been more extensively studied in children with APD, particularly the FFR. The central auditory nervous system function at different levels, from the brainstem to the cerebral auditory cortex, is reflected separately by short- to late-latency electrophysiological responses exhibiting possible abnormalities in the electrophysiological test results at different latencies in 
children with auditory processing deficits. These results may validate the role of both bottom-up and top-down factors in auditory information processing. The transfer of auditory information is not simply a step-by-step, hierarchically relayed structure of the auditory pathway (20). According to the ease of language underlying (ELU) model (130), when auditory signals are poor or listening under noise, increased auditory cognitive effort is necessary, with more than usual attention and memory involved in the comprehension of language. Therefore, for children with auditory processing abnormalities, electrophysiological tests at different latencies may be required clinically to assess the degree of impairment of the auditory processing function.

However, although the ASHA recommended diagnostic criteria for APD [the results were two standard deviations below the mean in at least one ear on two or more auditory behavioral tests (1)] have been recognized by AAA (2) and many experienced audiologists $(20,131,132)$, no unified gold standard for the diagnosis of APD has been established. Therefore, the criteria used to identify children with APD or children with sAPD also varied among the 14 included studies. Two studies $(33,38)$ used only the children auditory performance scale (48) and screening identification for targeting educational risk (49) and the screening checklist for auditory processing (SCAP) (133) to assess auditory processing abnormalities. Only 3 studies (34, $39,41)$ followed the diagnostic criteria recommended by ASHA to identify children with APD. Two studies $(44,45)$ used less than a certain percentage to define children with APD. Two studies $(36,37)$ used the criterion of a deficit in at least one of the auditory processing behavioral tests to evaluate children with APD. Additional studies $(33,42,43)$ have employed other modalities to identify children with APD. Although children with poor performance in auditory behavioral tests in these studies usually have poor electrophysiological test results, the electrophysiological characteristics of APD children may vary based on different diagnostic criteria. The conclusions drawn for children with sAPD do not necessarily apply to children diagnosed with APD (134); therefore, the conclusions obtained in this study may be more biased toward children with SAPD, which is also one of the limitations of this study. More studies need to be conducted for validation (135). Before then, controversial issues regarding the diagnostic criteria of APD is a critical first step to resolve. The BSA practice guidelines state that the establishment of a gold standard for the diagnosis and management of APD is highly recommended (136). Although many studies have confirmed that behavioral tests and electrophysiological tests can effectively identify damage to the central auditory nervous system in patients with APD, new, more precise, and effective tests for auditory processing still need to be developed (2).

Since APD is often comorbid with other disorders of mental development, such as language disorders, learning disabilities, and ADHD, among others. Behavioral tests used to identify APD often require the involvement of the child's language, attention, and cognition. Thus, it is of particular interest to consider when the results of auditory behavioral tests are poor in children with APD comorbid with other developmental disorders. Whether it is the problem of auditory processing itself or the result of other mental developmental disorders remains inconclusive. This systematic review was aimed at assessing the discriminative value of different methods of electroacoustic testing in children with APD or SAPD. With this objective considered, this review excludes studies in which the subjects were comorbid with other mental developmental disorders. Therefore, some equally important reports may not have been included in the study, such as (62,137-139). However, compared with other diseases, APD clinically coexists with other psychodevelopmental disorders $(10,12)$ in more children. Thus, more studies on the electrophysiological characteristics of children with APD combined with different psychodevelopmental disorders need to be performed in the future. Moreover, the diagnosis of children with APD is a complex process $(135,140)$ and requires the multidisciplinary involvement of audiologists during differential diagnosis, in conjunction with psychologists, speech pathologists, developmental behaviorists, and educators.

\section{CONCLUSION}

A systematic review of the 7 electrophysiological characteristics of children with sAPD suggests that auditory electrophysiological tests are valuable in identifying children with abnormal auditory processing. FFR has been widely studied, and its clinical application value has been confirmed. The clinical application value of middle- and late-latency physiological potentials in screening children with abnormal auditory processing needs more research for verification. Owing to the complexity of the central auditory system and the heterogeneity and comorbidity of auditory processing defects, the identification of auditory processing defects requires behavioral tests combined with electrophysiological tests of different latency responses. It also requires multidisciplinary collaboration in the differential diagnosis and intervention of auditory processing defects. In addition, the auditory electrophysiological characteristics of children with different mental developmental disorders need to be further examined. Standardized electrophysiological testing data of children in different regions and ages have to be established to provide a basis for the evaluation of the test results.

\section{LIMITATIONS}

No consensus has been reached regarding the diagnostic criteria for APD. Different auditory behavioral tests and measures were used to identify children with sAPD in the 14 included studies, although children with poorer performance in the behavioral tests generally showed poorer electrophysiological test results. However, the electrophysiological characteristics of children with SAPD identified in accordance with different diagnostic criteria may be more variable. Therefore, the electrophysiological test results of children with SAPD may not be applicable to all children with APD. Moreover, the study excluded the study of children with APD who are comorbid with other mental development disorders, possibly some equally important reports were excluded, and analyses of the discriminative value of different electrophysiological tests for auditory processing 
characteristics in children with different mental developmental disorders are needed in the future. Because the patterns presented by the results of the included studies were different, and not all studies could get a quantitative result, meta-analysis of the included studies could not be performed, so more high-quality clinical trial studies are needed to provide strong evidence. For electrophysiological testing, the stability of the testing tool, testing environment, and child status may affect the test results, and electrophysiological testing has the disadvantage of higher examination cost, which may limit the clinical applications of electrophysiological testing. Therefore, new auditory processing evaluation tools with enhanced sensitivity and specificity, which are suitable for clinical application and promotion, still need to be developed.

\section{DATA AVAILABILITY STATEMENT}

The original contributions presented in the study are included in the article/supplementary

\section{REFERENCES}

1. ASHA. (Central) Auditory Processing Disorders. (2005). Available online at: https://www.asha.org/POLICY/TR2005-00043/ (accessed August 6, 2020).

2. AAA, editor Clinical Practice Guidelines. Diagnosis, Treatment Management of Children Adults with Central Auditory Processing Disorder 2010: $A A A$ EUA. Available online at: https://www.audiology.org/publicationsresources/document-library/central-auditory-processing-disorder (accessed August 6, 2020)

3. Moore D, Campbell N, Rosen S, Bamiou D-E, Sirimanna T, Grant P, et al. Position Statement and Practice Guidance Auditory Processing Disorder (APD). (2018). Available online at: https://www.researchgate. net/publication/324437594_Position_Statement_and_Practice_Guidance_ Auditory_Processing_Disorder_APD (accessed August 10, 2020).

4. Myklebust HR. Auditory Disorders in Children: A Manual for Differential Diagnosis: Grune \& Stratton. (1954). Available online at: https://lib.ugent.be/ en/catalog/rug01:000960419 (accessed August 10, 2020).

5. Bocca E, Calearo C, Cassinari V. A new method for testing hearing in temporal lobe tumours; preliminary report. Acta Otolaryngol. (1954) 44:21921. doi: $10.3109 / 00016485409128700$

6. Hind S, Haines-Bazrafshan R, Benton C, Brassington W, Towle B, Moore D. Prevalence of clinical referrals having hearing thresholds within normal limits. Int J Audiol. (2011) 50:708-16. doi: 10.3109/14992027.2011.582049

7. Chermak GD, Hall JW III, Musiek FE. Differential diagnosis and management of central auditory processing disorder and attention deficit hyperactivity disorder. J Am Acad Audiol. (1999) 10:289-303.

8. Chermak G, Musiek FJG. Central Auditory Processing Disorders: New Perspectives. San Diego, CA: Singular Pub. (1997) Available online at: http:// citeseerx.ist.psu.edu/viewdoc/summary?doi=10.1.1.591.1050 (accessed August 20, 2020)

9. Riccio CA, Hynd GW, Cohen MJ, Hall J, Molt L. Comorbidity of central auditory processing disorder and attention-deficit hyperactivity disorder. J Am Acad Child Adolesc Psychiatry. (1994) 33:849-57. doi: 10.1097/00004583-199407000-00011

10. Sharma M, Purdy Suzanne C, Kelly Andrea S. Comorbidity of auditory processing, language, and reading disorders. J Speech Lang Hear Res. (2009) 52:706-22. doi: 10.1044/1092-4388(2008/07-0226)

11. King WM, Lombardino LJ, Crandell CC, Leonard CM. Comorbid auditory processing disorder in developmental dyslexia. Ear Hear. (2003) 24:44856. doi: 10.1097/01.AUD.0000090437.10978.1A

12. Jerger J, Musiek F. Report of the consensus conference on the diagnosis of auditory processing disorders in school-aged children. J Am Acad Audiol. (2000) 11:467-74. material, further inquiries can be directed to the corresponding author/s.

\section{AUTHOR CONTRIBUTIONS}

PL: conceptualization, methodology, and writing-original draft. HZ: data curation. MC: formal analysis. QH: writing-review and editing, supervision, project administration, and funding acquisition. XC: supervision, project administration, and funding acquisition. All authors contributed to the article and approved the submitted version.

\section{FUNDING}

This work was supported by the Key Young Medical Talents of Jiangsu Province (Project No. QNRC2016100), the High Level Talents of Jiangsu Province (Project No. WSN-165/WSW-125), and the Key Medical Science and Technology Development Projects in Nanjing (Project No. ZKX 18044).

13. Choi SMR, Kei J, Wilson WJ. Hearing and auditory processing abilities in primary school children with learning difficulties. Ear Hear. (2019) 40:7009. doi: 10.1097/aud.0000000000000652

14. Gokula R, Sharma M, Cupples L, Valderrama JT. Comorbidity of auditory processing, attention, and memory in children with word reading difficulties. Front Psychol. (2019) 10:2383. doi: 10.3389/fpsyg.2019.02383

15. Halliday LF, Tuomainen O, Rosen S. Auditory processing deficits are sometimes necessary and sometimes sufficient for language difficulties in children: evidence from mild to moderate sensorineural hearing loss. Cognition. (2017) 166:139-51. doi: 10.1016/j.cognition.2017.04.014

16. Chermak GD, Bellis TJ, Musiek FE. Neurobiology, cognitive science, and intervention. In: Chermak GD, Musiek FE, editors. Handbook of Central Auditory Processing Disorder: Comprehensive Intervention. Plural Publishing Inc. (2014). p. 3-38. Available online at: https://psycnet.apa.org/record/ 2014-01503-001 (accessed September 3, 2020).

17. Loo JHY, Rosen S, Bamiou D-E. Auditory training effects on the listening skills of children with auditory processing disorder. Ear Hear. (2016) 37:3847. doi: 10.1097/AUD.0000000000000225

18. Alonso R, Schochat E. The efficacy of formal auditory training in children with (central) auditory processing disorder: behavioral and electrophysiological evaluation. Brazil J Otorhinolaryngol. (2009) 75:72632. doi: 10.1016/S1808-8694(15)30525-5

19. Schow RL, Seikel JA. Screening for (central) auditory processing disorder. In: Handbook of (Central) Auditory Processing Disorder: Auditory Neuroscience and Diagnosis. Vol. 1 (2007). p. 137-59. Available online at: https://www.au diology.org/publications-resources/books/book-reviews/handbook-centralauditory-processing-disorder-volume-1 (accessed September 2, 2020)

20. Bellis TJ. Assessment and Management of Central Auditory Processing Disorders in the Educational Setting: From Science to Practice. Plural Publishing (2011). Available online at: https://www.pluralpublishing.com /publications/assessment-and-management-of-central-auditory-processin g-disorders-in-the-educational-setting-from-science-to-practice (accessed September 3, 2020).

21. Chermak GD, Silva ME, Nye J, Hasbrouck J, Musiek FE. An update on professional education and clinical practices in central auditory processing. J Am Acad Audiol. (2007) 18:428-52. doi: 10.3766/jaaa. 18.5.7

22. Wilson WJ, Arnott W. Using different criteria to diagnose (central) auditory processing disorder: how big a difference does it make? J Speech Lang Hear Res. (2013) 56:63-70. doi: 10.1044/1092-4388(2012/11-0352)

23. Emanuel DC, Ficca KN, Korczak P. Survey of the diagnosis and management of auditory processing disorder. Am J Audiol. (2011) 20:4860. doi: 10.1044/1059-0889(2011/10-0019) 
24. Vermiglio AJ. On diagnostic accuracy in audiology: central site of lesion and central auditory processing disorder studies. J Am Acad Audiol. (2016) 27:141-56. doi: 10.3766/jaaa.15079

25. Moore DR. Editorial: auditory processing disorder. Ear Hear. (2018) 39:61720. doi: 10.1097/AUD.0000000000000582

26. Keith WJ, Keith RW, Purdy SC. Letter to the editor: comments on the ear and hearing ban on certain auditory processing disorder articles re: Moore, D. R. (2018) Editorial: Auditory Processing Disorder, Ear Hear, 39, 617-620. Ear Hear. (2018) 39:1242-3. doi: 10.1097/AUD.0000000000000643

27. Sininger YS, Doyle KJ, Moore JK. The case for early identification of hearing loss in children: auditory system development, experimental auditory deprivation, and development of speech perception and hearing. Pediatr Clin North Am. (1999) 46:1-14. doi: 10.1016/S0031-395570077-8

28. Chowsilpa S, Bamiou D-E, Koohi N. Effectiveness of the auditory temporal ordering and resolution tests to detect central auditory processing disorder in adults with evidence of brain pathology: a systematic review and metaanalysis. Front Neurol. (2021) 12:591. doi: 10.3389/fneur.2021.656117

29. Carvalho NG, Ubiali T, Amaral M, Colella-Santos MF. Procedures for central auditory processing screening in schoolchildren. Brazil J Otorhinolaryngol. (2019) 85:319-28. doi: 10.1016/j.bjorl.2018.02.004

30. Liberati A, Altman DG, Tetzlaff J, Mulrow C, Gøtzsche PC, Ioannidis JPA, et al. The PRISMA statement for reporting systematic reviews and meta-analyses of studies that evaluate health care interventions: explanation and elaboration. J Clin Epidemiol. (2009) 62:e1-34. doi: 10.1016/j.jclinepi.2009.06.006

31. Wells GA, Shea B, O'Connell Da, Peterson J, Welch V, Losos M, et al. The Newcastle-Ottawa Scale (NOS) for Assessing the Quality Of Nonrandomised Studies in Meta-Analyses. Oxford (2000) Available online at: https://www. researchgate.net/publication/261773681_The_Newcastle-Ottawa_Scale_ NOS_for_Assessing_the_Quality_of_Non-Randomized_Studies_in_MetaAnalysis (accessed October 12, 2020).

32. Ankmnal-Veeranna S, Allan C, Allen P. Auditory brainstem responses in children with auditory processing disorder. J Am Acad Audiol. (2019) 30:904-17. doi: 10.3766/jaaa.18046

33. Abdollahi FZ, Lotfi Y, Moosavi A, Bakhshi E. Binaural interaction component of middle latency response in children suspected to central auditory processing disorder. Indian J Otolaryngol Head Neck Surg. (2019) 71:182-5. doi: 10.1007/s12070-017-1114-5

34. Koravand A, Jutras B, Lassonde M. Abnormalities in cortical auditory responses in children with central auditory processing disorder. Neuroscience. (2017) 346:135-48. doi: 10.1016/j.neuroscience.2017.01.011

35. Zakaria MN, Jalaei B. Test-retest reliability of speech-evoked auditory brainstem response in healthy children at a low sensation level. Int J Pediatr Otorhinolaryngol. (2017) 102:28-31. doi: 10.1016/j.ijporl.2017.08.033

36. Rocha-Muniz CN, Filippini R, Neves-Lobo IF, Rabelo CM, Morais AA, Murphy CF, et al. Can speech-evoked Auditory Brainstem Response become a useful tool in clinical practice? CoDAS. (2016) 28:7780. doi: $10.1590 / 2317-1782 / 20162014231$

37. Tomlin D, Rance G. Maturation of the central auditory nervous system in children with auditory processing disorder. Semi Hear. (2016) 37:7483. doi: $10.1055 / \mathrm{s}-0035-1570328$

38. Kumar P, Singh NK. BioMARK as electrophysiological tool for assessing children at risk for (central) auditory processing disorders without reading deficits. Hear Res. (2015) 324:54-8. doi: 10.1016/j.heares.2015.03.001

39. Rocha-Muniz CN, Befi-Lopes DM, Schochat E. Sensitivity, specificity and efficiency of speech-evoked ABR. Hear Res. (2014) 317:15-22. doi: 10.1016/j.heares.2014.09.004

40. Hornickel J, Knowles E, Kraus N. Test-retest consistency of speech-evoked auditory brainstem responses in typically-developing children. Hear Res. (2012) 284:52-8. doi: 10.1016/j.heares.2011.12.005

41. Schochat E, Musiek FE, Alonso R, Ogata J. Effect of auditory training on the middle latency response in children with (central) auditory processing disorder. Brazil J Med Biol Res. (2010) 43:777-85. doi: 10.1590/s0100-879x20100075 00069

42. Roggia SM, Colares NT. Mismatch negativity in patients with (central) auditory processing disorders. Brazil J Otorhinolaryngol. (2008) 74:70511. doi: 10.1016/s1808-8694(15)31380-x
43. Liasis A, Bamiou DE, Campbell P, Sirimanna T, Boyd S, Towell A. Auditory event-related potentials in the assessment of auditory processing disorders: a pilot study. Neuropediatrics. (2003) 34:23-9. doi: 10.1055/s-2003-38622

44. Delb W, Strauss DJ, Hohenberg G, Plinkert PK. The binaural interaction component (BIC) in children with central auditory processing disorders (CAPD). Int J Audiol. (2003) 42:401-12. doi: 10.3109/14992020309080049

45. Jirsa RE, Clontz KB. Long latency auditory event-related potentials from children with auditory processing disorders. Ear Hear. (1990) 11:22232. doi: 10.1097/00003446-199006000-00010

46. Starr A, Achor J. Auditory brain stem responses in neurological disease. Archiv Neurol. (1975) 32:7618. doi: 10.1001/archneur.1975.00490530083009

47. Stapells DR, Oates P. Estimation of the pure-tone audiogram by the auditory brainstem response: a review. Audiol Neurootol. (1997) 2:25780. doi: $10.1159 / 000259252$

48. Smoski W, Brunt MA, Tannahill JC. Children's Auditory Performance Scale (CHAPS). Tampa, FL: Educational Audiology Association (1998). Available online at: https://www.phonakpro.com/content/dam/phonakpro/gc_hq/e n/resources/counseling_tools/documents/child_hearing_assessment_child rens_auditory_performance_scale_chaps_2017.pdf (accessed October 20, 2020).

49. Anderson KL. Screening Instrument for Targeting Educational Risk. Danville, IL: Interstate (1989) Available online at: https:// successforkidswithhearingloss.com/wp-content/uploads/2011/08/SIFTER. pdf (accessed October 20, 2020).

50. Coffey EBJ, Nicol T, White-Schwoch T, Chandrasekaran B, Krizman J, Skoe E, et al. Evolving perspectives on the sources of the frequency-following response. Nat Commun. (2019) 10:5036. doi: 10.1038/s41467-019-13003-w

51. Skoe E, Kraus N. Auditory brain stem response to complex sounds: a tutorial. Ear Hear. (2010) 31:302-24. doi: 10.1097/AUD.0b013e3181cdb272

52. Song $\mathrm{JH}$, Nicol T, Kraus N. Test-retest reliability of the speechevoked auditory brainstem response. Clin Neurophysiol. (2011) 122:34655. doi: 10.1016/j.clinph.2010.07.009

53. Johnson KL, Nicol T, Zecker SG, Kraus N. Developmental plasticity in the human auditory brainstem. I Neurosci. (2008) 28:4000-7. doi: 10.1523/jneurosci.0012-08.2008

54. Cunningham J, Nicol T, Zecker SG, Bradlow A, Kraus N. Neurobiologic responses to speech in noise in children with learning problems: deficits and strategies for improvement. Clin Neurophysiol. (2001) 112:75867. doi: 10.1016/s1388-2457(01)00465-5

55. Sharma M, Purdy SC, Newall P, Wheldall K, Beaman R, Dillon H. Electrophysiological and behavioral evidence of auditory processing deficits in children with reading disorder. Clin Neurophysiol. (2006) 117:113044. doi: 10.1016/j.clinph.2006.02.001

56. Rocha-Muniz CN, Befi-Lopes DM, Schochat E. Investigation of auditory processing disorder and language impairment using the speech-evoked auditory brainstem response. Hear Res. (2012) 294:143-52. doi: 10.1016/j.heares.2012.08.008

57. Billiet CR, Bellis TJ. The relationship between brainstem temporal processing and performance on tests of central auditory function in children with reading disorders. J Speech Lang Hear Res. (2011) 54:22842. doi: 10.1044/1092-4388(2010/09-0239)

58. Banai K, Abrams D, Kraus N. Sensory-based learning disability: Insights from brainstem processing of speech sounds. Int J Audiol. (2007) 46:52432. doi: 10.1080/14992020701383035

59. King C, Warrier CM, Hayes E, Kraus N. Deficits in auditory brainstem pathway encoding of speech sounds in children with learning problems. Neurosci Lett. (2002) 319:111-5. doi: 10.1016/s0304-3940(01)02556-3

60. Sanfins MD, Borges LR, Ubiali T, Colella-Santos MF. Speech auditory brainstem response (speech ABR) in the differential diagnosis of scholastic difficulties. Brazil J Otorhinolaryngol. (2017) 83:112-6. doi: 10.1016/j.bjorl.2015.05.014

61. Dobie RA, Norton SJ. Binaural interaction in human auditory evoked potentials. Electroencephalogr Clin Neurophysiol. (1980) 49:303-13. doi: 10.1016/0013-4694(80)90224-2

62. Gopal KV, Pierel K. Binaural interaction component in children at risk for central auditory processing disorders. Scand Audiol. (1999) 28:7784. doi: 10.1080/010503999424798 
63. Picton TW, Hillyard SA, Krausz HI, Galambos R. Human auditory evoked potentials. I. Evaluation of components. Electroencephalogr Clin Neurophysiol. (1974) 36:179-90. doi: 10.1016/0013-4694(74)90155-2

64. Jerger S, Jerger J. Pediatric speech intelligibility test: St. Louis, MO: Auditec (1984).

65. Pereira LD. Processamento auditivo central: manual de avaliação. (1997). p. 231. Available online at: https://repositorio.usp.br/item/000972511 (accessed October 20, 2020).

66. Katz J. The SSW test: an interim report. J Speech Hear Disord. (1968) 33:132-46. doi: 10.1044/jshd.3302.132

67. Musiek FE. Assessment of central auditory dysfunction: the dichotic digit test revisited. Ear Hear. (1983) 4:7983. doi: 10.1097/00003446-198303000-00002

68. Shafer VL, Ponton C, Datta H, Morr ML, Schwartz RG. Neurophysiological indices of attention to speech in children with specific language impairment. Clin Neurophysiol. (2007) 118:1230-43. doi: 10.1016/j.clinph.2007.02.023

69. Koravand A, Jutras B, Lassonde M. Auditory event related potentials in children with peripheral hearing loss. Clin Neurophysiol. (2013) 124:143947. doi: 10.1016/j.clinph.2013.01.016

70. Sharma A, Martin K, Roland P, Bauer P, Sweeney MH, Gilley P, et al. P1 latency as a biomarker for central auditory development in children with hearing impairment. J Am Acad Audiol. (2005) 16:56473. doi: $10.3766 /$ jaaa. 16.8 .5

71. Chang HW, Dillon H, Carter L, van Dun B, Young ST. The relationship between cortical auditory evoked potential (CAEP) detection and estimated audibility in infants with sensorineural hearing loss. Int J Audiol. (2012) 51:663-70. doi: 10.3109/14992027.2012.690076

72. Ceponiene R, Torki M, Alku P, Koyama A, Townsend J. Eventrelated potentials reflect spectral differences in speech and non-speech stimuli in children and adults. Clin Neurophysiol. (2008) 119:156077. doi: 10.1016/j.clinph.2008.03.005

73. Näätänen R, Tervaniemi M, Sussman E, Paavilainen P, Winkler I. "Primitive intelligence" in the auditory cortex. Trends Neurosci. (2001). 24:2838. doi: 10.1016/s0166-2236(00)01790-2

74. Morr ML, Shafer VL, Kreuzer JA, Kurtzberg D. Maturation of mismatch negativity in typically developing infants and preschool children. Ear Hear. (2002) 23:118-36. doi: 10.1097/00003446-200204000-00005

75. Rudmin F, Normandin N. Experimental dichotic tests in French modeled on SSW design. Hum Commun Canada. (1983) 7:348-60.

76. Lynch A, Normandin N. SSI: Élaboration d'une version française et application auprès d'une population d'enfants avec troubles d'apprentissage (Unpublished master's thesis). University of Montreal, Montreal, QC, Canada (1983).

77. Musiek FE. Frequency (pitch) and duration pattern tests. J Am Acad Audiol. (1994) 5:265-8.

78. Keith RW. Random Gap Detection Test. St Louis, MO: Auditec (2000). p. 13.

79. Finley WW, Faux SF, Hutcheson J, Amstutz L. Long-latency event-related potentials in the evaluation of cognitive function in children. Neurology. (1985) 35:323-7. doi: 10.1212/wnl.35.3.323

80. Evans JL, Selinger C, Pollak SD. P300 as a measure of processing capacity in auditory and visual domains in specific language impairment. Brain Res. (2011) 1389:93-102. doi: 10.1016/j.brainres.2011.02.010

81. Bellis TJ. Understanding Auditory Processing Disorders in Children. American Speech-Language-Hearing Association (2004). p. 5157-59.

82. Phillips DP editor. Central Auditory System and Central Auditory Processing Disorders: Some Conceptual Issues. (2002). Available online at: http://www. brainmaster.com/software/pubs/brain/Phillips-auditory-processing_4_23_ 2002\%20(1).pdf (accessed October 20, 2020).

83. Benasich AA, Thomas JJ, Choudhury N, Leppänen PH. The importance of rapid auditory processing abilities to early language development: evidence from converging methodologies. Dev Psychobiol. (2002) 40:27892. doi: 10.1002/dev.10032

84. McArthur GM, Bishop DV. Frequency discrimination deficits in people with specific language impairment: reliability, validity, and linguistic correlates. $J$ Speech Lang Hear Res. (2004) 47:527-41. doi: 10.1044/1092-4388(2004/041)

85. Allen P, Allan C. Auditory processing disorders: relationship to cognitive processes and underlying auditory neural integrity. Int $J$ Pediatr Otorhinolaryngol. (2014) 78:198-208. doi: 10.1016/j.ijporl.2013.10.048
86. Dawes P, Sirimanna T, Burton M, Vanniasegaram I, Tweedy F, Bishop DV. Temporal auditory and visual motion processing of children diagnosed with auditory processing disorder and dyslexia. Ear Hear. (2009) 30:67586. doi: 10.1097/AUD.0b013e3181b34cc5

87. Tomlin D, Dillon H, Sharma M, Rance G. The impact of auditory processing and cognitive abilities in children. Ear Hear. (2015) 36:52742. doi: 10.1097/aud.0000000000000172

88. Sharma M, Dhamani I, Leung J, Carlile S. Attention, memory, and auditory processing in 10- to 15-year-old children with listening difficulties. J Speech Lang Hear Res. (2014) 57:2308-21. doi: 10.1044/2014_jslhr-h-13-0226

89. Magimairaj BM, Nagaraj NK. Working memory and auditory processing in school-age children. Lang Speech Hear Serv Sch. (2018) 49:40923. doi: 10.1044/2018 lshss-17-0099

90. Weihing J, Chermak GD, Musiek FE. Auditory training for central auditory processing disorder. Semi Hear. (2015) 36:199-215. doi: 10.1055/s-0035-1564458

91. Santos TSd, Mancini PC, Sancio LP, Castro AR, Labanca L, Resende LMD. Findings in behavioral and electrophysiological assessment of auditory processing. Audiol Commun Res. (2015) 20:225-32. doi: 10.1590/2317-6431-2015-1589

92. Parthasarathy TK. Electrophysiologic assessment of CAPD: a review of the basics. Hear J. (2000) 53:52-4. Available online at: https://journals.lww.com/ thehearingjournal/Citation/2000/04000/Electrophysiologic_assessment_of_ CAPD_A_review_of.6.aspx (accessed October 28, 2020).

93. Tzounopoulos T, Kraus N. Learning to encode timing: mechanisms of plasticity in the auditory brainstem. Neuron. (2009) 62:4639. doi: 10.1016/j.neuron.2009.05.002

94. Despland PA, Galambos R. The auditory brainstem response (ABR) is a useful diagnostic tool in the intensive care nursery. Pediatr Res. (1980) 14:154-8. doi: 10.1203/00006450-198002000-00018

95. Møller AR. Neural mechanisms of BAEP. Electroencephalogr Clin Neurophysiol Suppl. (1999) 49:27-35.

96. Starr A. Correlation between confirmed sites of neurological lesions and abnormalities of far-field auditory brainstem responses. Electroencephalogr Clin Neurophysiol. (1976) 41:595-608. doi: 10.1016/0013-469490005-5

97. Kraus N, Nicol T. Brainstem origins for cortical 'what' and 'where' pathways in the auditory system. Trends Neurosci. (2005) 28:17681. doi: 10.1016/j.tins.2005.02.003

98. Johnson KL, Nicol TG, Zecker SG, Kraus N. Auditory brainstem correlates of perceptual timing deficits. J Cogn Neurosci. (2007) 19:37685. doi: 10.1162/jocn.2007.19.3.376

99. Johnson KL, Nicol TG, Kraus N. Brain stem response to speech: a biological marker of auditory processing. Ear Hear. (2005) 26:42434. doi: 10.1097/01.aud.0000179687.71662.6e

100. Skoe E, Kraus N. Musical training heightens auditory brainstem function during sensitive periods in development. Front Psychol. (2013) 4:622. doi: 10.3389/fpsyg.2013.00622

101. Akhoun I, Gallégo S, Moulin A, Ménard M, Veuillet E, BergerVachon C, et al. The temporal relationship between speech auditory brainstem responses and the acoustic pattern of the phoneme /ba/ in normal-hearing adults. Clin Neurophysiol. (2008) 119:922-33. doi: 10.1016/j.clinph.2007.12.010

102. Banai K, Hornickel J, Skoe E, Nicol T, Zecker S, Kraus N. Reading and subcortical auditory function. Cereb Cortex. (2009) 19:2699-707. doi: 10.1093/cercor/bhp024

103. Hornickel J, Lin D, Kraus N. Speech-evoked auditory brainstem responses reflect familial and cognitive influences. Dev Sci. (2013) 16:101-10. doi: 10.1111/desc.12009

104. Krishnamurti S, Forrester J, Rutledge C, Holmes GW. A case study of the changes in the speech-evoked auditory brainstem response associated with auditory training in children with auditory processing disorders. Int J Pediatr Otorhinolaryngol. (2013) 77:594-604. doi: 10.1016/j.ijporl.2012.12.032

105. Debruyne F. Binaural interaction in early, middle and late auditory evoked responses. Scand Audiol. (1984) 13:293-6. doi: 10.3109/010503984090 42139

106. Dobie RA, Wilson MJ. Binaural interaction in auditory brain-stem responses: effects of masking. Electroencephalogr Clin Neurophysiol. (1985) 62:5664. doi: 10.1016/0168-5597(85)90035-8 
107. Hendler T, Squires NK, Emmerich DS. Psychophysical measures of central auditory dysfunction in multiple sclerosis: neurophysiological and neuroanatomical correlates. Ear Hear. (1990) 11:40316. doi: 10.1097/00003446-199012000-00002

108. Fowler CG, Swanson MR. Validation of addition and subtraction of ABR waveforms. Scand Audiol. (1988) 17:1959. doi: $10.3109 / 01050398809070704$

109. Jiang ZD, Tierney TS. Binaural interaction in human neonatal auditory brainstem. Pediatr Res. (1996) 39(4 Pt 1):70814. doi: 10.1203/00006450-199604000-00024

110. Jerger J, Chmiel R, Tonini R, Murphy E, Kent M. Twin study of central auditory processing disorder. J Am Acad Audiol. (1999) 10:521-8.

111. Jerger J, Johnson K, Jerger S, Coker N, Pirozzolo F, Gray L. Central auditory processing disorder: a case study. J Am Acad Audiol. (1991) 2:36-54.

112. Van Yper LN, Vermeire K, De Vel EF, Battmer RD, Dhooge IJ. Binaural interaction in the auditory brainstem response: a normative study. Clin Neurophysiol. (2015) 126:772-9. doi: 10.1016/j.clinph.2014.07.032

113. Ferber AT, Benichoux V, Tollin DJ. Test-retest reliability of the binaural interaction component of the auditory brainstem response. Ear Hear. (2016) 37:e291-301. doi: 10.1097/aud.0000000000000315

114. Jerger J, Johnson K. Interactions of age, gender, and sensorineural hearing loss on ABR latency. Ear Hear. (1988) 9:168-76. doi: 10.1097/00003446-198808000-00002

115. Milicić D, Alçada MN, Pais Clemente L, Vecerina-Volić S, Jurković J, Pais Clemente M. A study of auditory afferent organization in children with dyslalia. Int J Pediatr Otorhinolaryngol. (1998) 46:4356. doi: 10.1016/s0165-5876(98)00135-9

116. Musiek F, Charette L, Kelly T, Lee WW, Musiek E. Hit and false-positive rates for the middle latency response in patients with central nervous system involvement. J Am Acad Audiol. (1999) 10:124-32.

117. Knight RT, Scabini D. Anatomic bases of event-related potentials and their relationship to novelty detection in humans. J Clin Neurophysiol. (1998) 15:3-13. doi: 10.1097/00004691-199801000-00003

118. Luck S. An Introduction to Event-Related Potentials and Their Neural Origins. An Introduction to the Event-Related Potential Technique (2005). p. 107.

119. Ceponiene R, Rinne T, Näätänen R. Maturation of cortical sound processing as indexed by event-related potentials. Clin Neurophysiol. (2002) 113:87082. doi: 10.1016/s1388-2457(02)00078-0

120. Sharma A, Kraus N, McGee TJ, Nicol TG. Developmental changes in P1 and N1 central auditory responses elicited by consonantvowel syllables. Electroencephalogr Clin Neurophysiol. (1997) 104:540-5. doi: 10.1016/s0168-5597(97)00050-6

121. Picton TW, Alain C, Otten L, Ritter W, Achim A. Mismatch negativity: different water in the same river. Audiol Neurootol. (2000) 5:11139. doi: $10.1159 / 000013875$

122. Alain C, Woods DL, Covarrubias D. Activation of duration-sensitive auditory cortical fields in humans. Electroencephalogr Clin Neurophysiol. (1997) 104:531-9. doi: 10.1016/s0168-5597(97)00057-9

123. Ponton CW, Eggermont JJ, Kwong B, Don M. Maturation of human central auditory system activity: evidence from multi-channel evoked potentials. Clin Neurophysiol. (2000) 111:220-36. doi: 10.1016/s1388-2457(99)00236-9

124. Stothart G, Kazanina N. Auditory perception in the aging brain: the role of inhibition and facilitation in early processing. Neurobiol Aging. (2016) 47:23-34. doi: 10.1016/j.neurobiolaging.2016.06.022

125. Kraus N, McGee T, Micco A, Sharma A, Carrell T, Nicol T. Mismatch negativity in school-age children to speech stimuli that are just perceptibly different. Electroencephalogr Clin Neurophysiol. (1993) 88:123-30. doi: 10.1016/0168-5597(93)90063-u

126. Gu C, Bi HY. Auditory processing deficit in individuals with dyslexia: A meta-analysis of mismatch negativity. Neurosci Biobehav Rev. (2020) 116:396-405. doi: 10.1016/j.neubiorev.2020.06.032

127. Chen TC, Hsieh MH, Lin YT, Chan PS, Cheng CH. Mismatch negativity to different deviant changes in autism spectrum disorders: a meta-analysis. Clin Neurophysiol. (2020) 131:766-77. doi: 10.1016/j.clinph.2019.10.031

128. Polich J. Neuropsychology of P300. In: Luck SJ, Kappenman ES, editors. The Oxford Handbook of Event-Related Potential Components. Oxford, CA: Oxford University Press (2012). p. 159-88.

129. Jirsa RE. The clinical utility of the P3 AERP in children with auditory processing disorders. $J$ Speech
Hear Res. (1992) 35:903-12. doi: 10.1044/jshr.3504.

903

130. Edwards B. A model of auditory-cognitive processing and relevance to clinical applicability. Ear Hear. (2016) 37(Suppl. 1):85-91s. doi: 10.1097/aud.0000000000000308

131. Chermak GD. Central Auditory Processing Disorders. (1997). Available online at: http://citeseerx.ist.psu.edu/viewdoc/summary?doi=10.1.1.591. 1050 (accessed December 3, 2020).

132. Chermak GD, Musiek FE. Handbook of Central Auditory Processing Disorder, Volume II: Comprehensive Intervention. Plural Publishing (2013). Available online at: https://books.google.com.hk/books?hl=zh-CN\&lr=\&id= ByaYCwAAQBAJ\&oi=fnd\&pg=PR5\&dq=Handbook+of +central+auditory + processing+disorder,+volume+II:+Comprehensive+intervention:+Plural+ Publishing\%3B\&ots=VdCyVxOC06\&sig=OuMi6i0AXxNGVpATkYVGN09okU\&redir_esc $=y \& h l=z h C N \&$ sourceid $=\mathrm{cndr} \# \mathrm{v}=$ onepage $\& \mathrm{q}=$ Handbook\%20of\%20central\%20auditory\%20processing\%20disorder\%2C \%20volume\%20II\%3A\%20Comprehensive\%20intervention\%3A\%20Plural \%20Publishing\%3B\&f=false (accessed December 2, 2020).

133. Yathiraj A, Mascarenhas K. Auditory profile of children with suspected auditory processing disorder. J Ind Speech Hear Assoc. (2004) 18:6-14. Available online at: https://www.researchgate.net/publication/284632634_ Auditory_profile_of_children_with_suspected_auditory_processing_ disorder (accessed December 13, 2020).

134. Chermak GD, Musiek FE, Weihing J. Beyond controversies: the science behind central auditory processing disorder. Hear Rev. (2017) 24:204. Available online at: http://www.hearingreview.com/2017/05/beyond-co ntroversies-science-behind-central-auditory-processing-disorder/ (accessed December 13, 2020).

135. Iliadou V, Kiese-Himmel C. Common misconceptions regarding pediatric auditory processing disorder. Front Neurol. (2017) 8:732. doi: $10.3389 /$ fneur.2017.00732

136. Moore D, Campbell N, Rosen S, Bamiou D-E, Sirimanna T, Grant P, et al. British Society of Audiology Position Statement \& Practice Guidance: Auditory Processing Disorder (APD). (2018). Available online at: https:// www.thebsa.org.uk/resources/position-statement-practice-guidanceauditory-processing-disorder-apd/ (accessed December 6, 2020).

137. Jirsa RE. Maximum length sequences-auditory brainstem responses from children with auditory processing disorders. J Am Acad Audiol. (2001) 12:155-64.

138. Gopal KV, Kowalski J. Slope analysis of Auditory Brainstem Responses in children at risk of central auditory processing disorders. Scand Audiol. (1999) 28:85-90. doi: 10.1080/010503999424806

139. Sharma M, Purdy SC, Kelly AS, editors. The contribution of speechevoked cortical auditory evoked potentials to the diagnosis and measurement of intervention outcomes in children with auditory processing disorder. In: Seminars in Hearing. Sydney, NSW: Thieme Medical Publishers (2014). doi: $10.1055 / \mathrm{s}-0033-1363524$

140. Iliadou VV, Ptok M, Grech H, Pedersen ER, Brechmann A, Deggouj $\mathrm{N}$, et al. A European perspective on auditory processing disordercurrent knowledge and future research focus. Front Neurol. (2017) 8:622. doi: 10.3389/fneur.2017.00622

Conflict of Interest: The authors declare that the research was conducted in the absence of any commercial or financial relationships that could be construed as a potential conflict of interest.

Publisher's Note: All claims expressed in this article are solely those of the authors and do not necessarily represent those of their affiliated organizations, or those of the publisher, the editors and the reviewers. Any product that may be evaluated in this article, or claim that may be made by its manufacturer, is not guaranteed or endorsed by the publisher.

Copyright $\odot 2021 \mathrm{Liu}, \mathrm{Zhu}$, Chen, Hong and Chi. This is an open-access article distributed under the terms of the Creative Commons Attribution License (CC BY). The use, distribution or reproduction in other forums is permitted, provided the original author(s) and the copyright owner(s) are credited and that the original publication in this journal is cited, in accordance with accepted academic practice. No use, distribution or reproduction is permitted which does not comply with these terms. 